Correction

\title{
Correction: Ma, X. et al. Conducting Polymeric Nanocomposites with a Three-Dimensional Co-flow Microfluidics Platform. Micromachines, 2019, 10, 383
}

\author{
Xiaodong Ma ${ }^{1,+}$, Yuezhou Zhang ${ }^{1,2, *,+} \mathbb{C}$ and Korbinian Weisensee ${ }^{2}$ \\ 1 Xi'an Institute of Flexible Electronics \& Xi'an Institute of Biomedical Materials and Engineering, \\ Northwestern Polytechnical University (NPU), Xi'an 710072, China; 13851280968@163.com \\ 2 Department of Pharmaceutical Science Laboratory, Åbo Akademi University, 20520 Turku, Finland; \\ zyuezhou@126.com \\ * Correspondence: iamyzzhang@nwpu.edu.cn; Tel.: +86-29-88460924 \\ + These authors equally contributed to this work.
}

The authors would like to indicate the following financial support they received to the Funding Section of their published paper [1]: "This research was supported by the Fundamental Research Funds for the Central Universities of China, grant number 31020190QD030."

The changes do not affect the scientific results. We apologize for any inconvenience caused to the readers. The manuscript will be updated, and the original will remain online on the article webpage, with a reference to this correction.

\section{Reference}

1. Ma, X.; Zhang, Y.; Weisensee, K. Conducting Polymeric Nanocomposites with a Three-Dimensional Co-flow Microfluidics Platform. Micromachines 2019, 10, 383. [CrossRef] [PubMed]

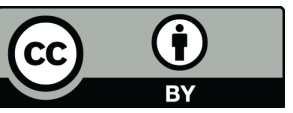

(C) 2019 by the authors. Licensee MDPI, Basel, Switzerland. This article is an open access article distributed under the terms and conditions of the Creative Commons Attribution (CC BY) license (http://creativecommons.org/licenses/by/4.0/). 